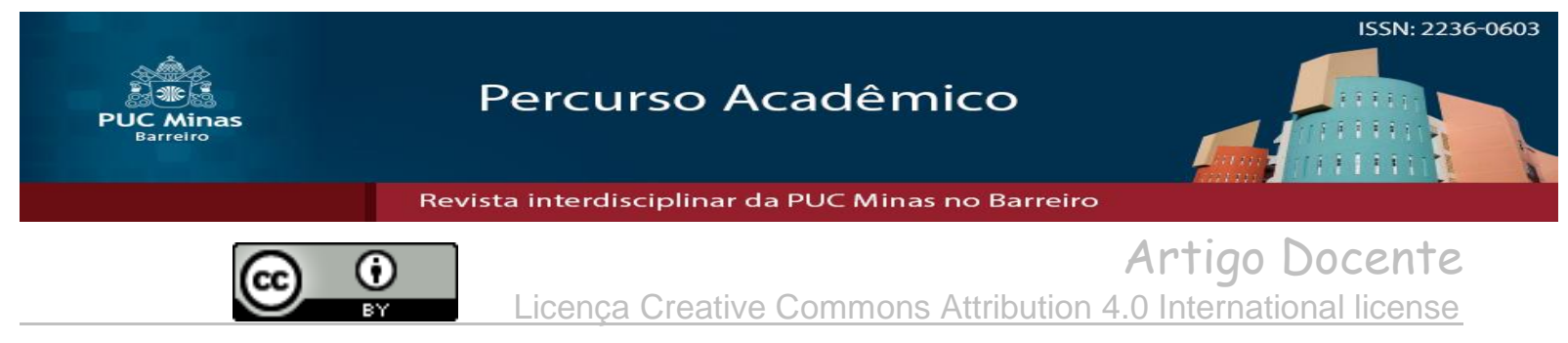

\title{
Educação e cidadania: qual cidadania?
}

\section{Education and citizenship: which citizenship?}

\author{
José Newton Tomazzoni Tavares ${ }^{1}$
}

\begin{abstract}
Resumo
A presente reflexão quer trazer à luz a discussão sobre a ambiguidade do conceito de cidadania bem como sua relação histórica com o processo educacional em nosso país. Em que pese sua aparente estabilidade, tacitamente consensual, o conceito de cidadania não é algo acabado, previamente definido. Ao contrário, o conceito de cidadania é resultado de longas elaborações teóricas que de modo algum excluem as concepções políticas que o constrói. Assim, ao propor uma educação para a cidadania, é necessário antes definirmos sobre qual cidadania estamos falando. Quais os pressupostos políticos ideológicos que estão imbricados na sua construção e a quem tal cidadania pretende alcançar. Portanto, essa é a questão que se coloca essa pequena reflexão: Qual cidadania queremos quando falamos em cidadania? Esse conceito é unívoco? Estamos todos de acordo com seu significado? Quando se propõe que a educação seja uma educação para a cidadania, é preciso explicitar antes sobre qual cidadania se esta falando. Mais do que isso: sabemos as implicações políticas implícitas desse conceito? A política educacional brasileira nunca tratou dessa questão de forma mais sistemática.
\end{abstract}

Palavras-chave: Cidadania. Democracia. Educação. História da Educação.

\begin{abstract}
The present reflection aims at bringing to light the discussion about the ambiguity of the citizenship concept as well as its historical relation with the educational process in our country. In spite of its apparent stability, tacitly consensual, the citizenship concept is not something finished, previously defined. On the contrary, the citizenship concept is the result of long theoretical elaborations which in no way exclude the political conceptions that construct it. Therefore, when an education for citizenship is proposed, it is necessary to define before which citizenship we are talking about, which ideological political pressupositions are tangled together in its construction and who such citizenship intends to reach. Therefore, this is the question that poses this small reflection: What citizenship do we want when we talk about citizenship? Is this concept univocal? Are we all in agreement with its meaning? When it is proposed that education be an education for citizenship, it is necessary to make explicit beforehand on which citizenship is speaking. More than that: do we know the implicit political implications of this concept? Brazilian education policy has never addressed this issue in a more systematic way.
\end{abstract}

Keywords: Citizenship. Democracy. Education. History of Education.

Artigo recebido em 10 de Novembro de 2016 e aprovado em 22 de Março de 2017.

${ }^{1}$ Professor do Departamento de Filosofia da PUC-MG. Mestre em educação e doutorando em Filosofia e Política da Educação pela PUC-MG. E-mail: jnewtont@uol.com.br 


\section{Introdução}

A educação para a cidadania parece ser uma questão resolvida. Em documentos oficiais das políticas públicas para a educação contemporânea, nas falas dos professores e alunos e até mesmo em discussões cotidianas de pessoas alheias ao meio educacional, educar para a cidadania é uma verdade tácita estabelecida sem muita discussão. Todos parecem querer uma educação para a cidadania. O que estaria em jogo seria como se daria essa educação para a cidadania. O problema não estaria no conceito, aparentemente resolvido e supostamente entendido, mas em sua implementação, ou seja, como essa educação se processaria: quais os métodos e teorias pedagógicas seriam melhores para transformar os alunos em cidadãos.

A questão que se coloca a essa pequena reflexão é justamente sobre o conceito de cidadania. Quando se pugna para que a educação seja uma educação para a cidadania, é preciso explicitar antes de qual cidadania se está falando. Todavia, a política educacional brasileira nunca tratou dessa questão, a não ser de modo genérico.

Esta questão se impõe, a nosso ver, porque entendemos que a educação escolar sempre está a serviço de um tipo determinado de cidadania, e que esta é a pedra de toque do controle social e econômico. Pode significar conformismo e obediência, mas, dependendo de como o processo educacional se desenrola na triangulação professoraluno-conhecimento, pode também levar ao desenvolvimento intelectual e aumentar a compreensão do educando em relação ao meio natural ou socialmente criado onde vive, e, assim, atuar de um modo não coercitivo, contribuindo para a formação de um indivíduo crítico/reflexivo.

Nesse sentido, o modo como a educação escolar se desenvolve não é neutro em relação ao tipo de cidadania que se busca. Diferentes concepções de educação, mesmo implícitas às vezes, sempre estão presentes no planejamento educacional e curricular. Quando a escola seleciona objetivos educacionais, conteúdos e critérios de avaliação do aprendizado está optando por um determinado projeto educacional, que de forma alguma é neutro em relação à cidadania.

A forma de pensar o processo educacional tem variado ao longo do tempo, o mesmo podendo ser dito em relação ao próprio conceito de cidadania, com seus diferentes significados percorrendo a história política da humanidade. Em Atenas, cidadão é aquele homem livre, que participa das decisões políticas; nos séculos XVII, 
XVIII e XIX, quando se edifica o Estado/Nação com base na cidadania, a educação se torna essencial para a constituição da nacionalidade. Isto é, para a consolidação da nação burguesa é fundamental que os valores culturais sejam socializados para todos, através do processo educacional. No século XX, o deslocamento da educação do elemento político para o técnico obscurece essa relação.

O surgimento da administração científica, no momento em que o capitalismo inicia o desenvolvimento da sua fase monopolista, retira da educação o seu conteúdo político. Não se fala mais em educação democrática ou autoritária; há apenas a educação, que deve ser, eficaz e eficientemente, fornecida a crianças e jovens. Triunfa a racionalidade científica; administrar a escola, escolher e organizar os conteúdos curriculares são questões não mais políticas, apenas técnicas. A execução é separada do pensar; o bom professor é aquele que executa de modo competente o que foi pensado por outros. É o "fordismo" na sala de aula. Sobre essa forma de pensar a educação nos expõe Palma Filho (1998, p.3):

\begin{abstract}
Nada mais político do que esse modo neutro, "científico", de pensar a educação. Os setores hegemônicos estavam defendendo o tipo de educação e de cidadania que melhor convinha para o desenvolvimento capitalista naquele momento da história humana - "predomínio da cultura do positivismo" é a adequada expressão cunhada por Giroux (1986) para essa etapa histórica que antecede o advento do fascismo na Europa.
\end{abstract}

A partir da segunda metade do século XX, a educação volta a se preocupar com a cidadania. Incorporada definitivamente ao novo modo de inserção no mundo contemporâneo, a cidadania é vista como condição indispensável para a construção de uma sociabilidade baseada nos direitos fundamentais do homem. Nesse sentido, a educação, como forma fundamental de socialização, só será uma educação de qualidade se educar para a cidadania. Isso parece claro. O que não se evidencia é o tipo de cidadania que se persegue.

Assim, a cidadania não é uma questão fechada, consensual e resolvida. Ela é, na verdade, um campo de batalha. Um espaço de lutas onde os projetos educacionais se confrontam para o estabelecimento de uma determinada e hegemônica concepção de educação, consoante a um tipo de projeto político.

Entendemos cidadania como o exercício dos direitos e deveres civis, políticos e sociais estabelecidos na nossa Constituição de 1988. Tal exercício implica que os direitos e deveres estão interligados, e o respeito e o cumprimento de ambos contribuem para uma sociedade mais equilibrada, mais livre e mais igualitária. No entanto, como campo de batalha, a cidadania vai se diferenciar, não pelo conceito de liberdade, central 
em todos os paradigmas, mas na forma como cada um deles recepciona o conceito de igualdade.

\section{A nova ordem mundial: o campo da cidadania}

Segundo o senso comum vigente nos meios acadêmicos, nos meios de comunicação e até mesmo nos meios populares, estaríamos vivendo hoje um mundo totalmente diferente daquele projetado pela visão iluminista da modernidade, constituindo, assim, uma nova ordem mundial. Essa nova ordem estaria marcada pela revolução tecnológica, capaz de lidar com a produção e a transmissão de informações em extraordinária velocidade, em um processo de globalização não só da cultura, mas também da economia e da política. Tal globalização, segundo Severino (2000, p. 66):

Tratar-se-ia de um momento marcado pelo privilegiamento da iniciativa privada, pela minimalização da ingerência do Estado nos negócios humanos, pela maximalização das leis do mercado, pela ruptura de todas as fronteiras.

É o momento em que o capitalismo chega na sua fase internacional. O rompimento de todas as fronteiras é imprescindível para que o capital possa se expandir e, ao mesmo tempo, concentrar os lucros em alguns centros específicos. Os mercados nacionais se tornam insuficientes para a expansão do capital financeiro, e isso pede uma internacionalização da economia. A fábrica agora se expande e engloba o planeta em uma grande linha de produção em busca da mão de obra mais barata. Para Ianni (1988, p.28):

O que esta em causa é a busca de maior e crescente produtividade,
competitividade e lucratividade, tendo em conta mercados nacionais,
regionais e mundiais. Daí a impressão de que o mundo se transforma no
território de uma vasta e complexa fábrica global e, ao mesmo tempo, em
shopping Center global e Disneylândia global.

Filosoficamente estaria em pauta uma crítica profunda às formas de expressão da razão teórica da modernidade, propondo-se a desconstrução de todos os discursos por ela produzidos, todos colocados sob suspeita, até mesmo aquelas da própria ciência. Todos os grandes sistemas teóricos interpretativos da realidade humana são caracterizados como metanarrativas e, como tal, desconsiderados. Tal situação se configuraria como uma situação histórica denominada pós-modernidade.

No entanto, este modo de ver e existir atuais, de perfil assumidamente neoliberal, com suas decorrências e expressões no plano cultural, com sua exarcebação do individualismo, do produtivismo, do consumismo, da indústria cultural, da 
mercantilização até mesmo dos bens simbólicos não instauram nenhuma pósmodernidade. Concordamos com Severino (2000, p. 66):

\begin{abstract}
Com efeito, o que está de fato acontecendo é a plena maturação das premissas e promessas da própria modernidade. Nada mais moderno do que esta expansão e consolidação do capitalismo, envolvido numa aura ideológica de liberalismo extremado; nada mais moderno do que esta tecnização, viabilizada pela revolução informacional.
\end{abstract}

Segundo o mesmo autor, a modernidade está realizando as promessas embutidas em seu projeto civilizatório. Nada mais moderno do que o individualismo egoísta dos dias de hoje. No fundo, é a mesma racionalidade que continua dirigindo os rumos da história humana, em que pese as críticas que são feitas à sua forma de expressão até o século XIX. (SEVERINO, 2000).

No entanto, não há dúvidas que tal contexto configura uma situação nova. Há uma nova sensibilidade perpassando a cultura ocidental contemporânea. Isso não podemos negar e nem recusar. $O$ que se impõe de forma mais contundente é um reequacionamento, da nossa parte, dos lugares que ocupamos nessa nova dinâmica sociocultural. Não há uma pós-modernidade, mas há uma ideologia pós-moderna e isso nos impõe uma atenção redobrada com relação a esse momento histórico, não nos deixando levar nem por uma atitude de mera anatematização moralizante ou saudosista, nem por um deslumbramento alienante. É preciso que façamos uma análise crítica e contundente, sob pena de não percebermos as armadilhas que se escondem por trás dessa ideologia.

Com relação ao conceito de cidadania, tal ineficiência de uma análise mais profunda do contexto contemporâneo, pode nos ser fortemente danosa se quisermos uma educação crítica, pois em tal situação, caracterizada pela ideologia pós-moderna, o conceito de cidadania é profundamente ressignificado. O neoliberalismo o interpreta agora como a condição de poder se inserir no mercado como um consumidor.

Ao interpretar a realidade como um rizoma, a ideologia pós-moderna neoliberal rompe com todas as metanarrativas construídas pela Modernidade. E isso não parece ser inocente. Ora, o grande conceito forjado pela modernidade é o conceito de totalidade. Tal categoria significa a percepção da realidade social como um todo orgânico, estruturado, no qual não se pode entender um elemento, um aspecto, uma dimensão, sem perder a sua relação com o conjunto. Ao romper com a totalidade, equivocadamente relacionando-a com totalitarismo, a chamada pós-modernidade implementa uma visão de mundo fragmentária. Sua epistemologia parte do pressuposto 
de que não há uma realidade, mas várias, dependendo do olhar. Para tal ideologia, a realidade seria uma construção do sujeito. Como decorrência, perdendo a visão do todo, se aposta apenas em visões parciais e individualizantes da realidade, agora vista como um grande caleidoscópio. Tal epistemologia se enquadra bem ao gosto do relativismo pós-moderno.

A nosso ver, tal construção teórica, deslegitimando o conceito de totalidade, inviabiliza uma postura crítica porque desloca o olhar da perspectiva da classe para a cultura. Entendemos que as questões culturais são prementes e importantes, mas desconectadas das relações sociais de produção capitalistas que as engendram, acabam por desfazer o liame que as ligam a uma totalidade maior configurada como profundamente excludente. As relações econômicas excludentes, produtoras de profundas desigualdades, são escamoteadas em função de uma visão apenas cultural ou de foro íntimo. A cidadania se resume, nesse paradigma, em ações meramente tópicas como respeitar vagas para deficientes, indignar-se com a discriminação racial ou fazer coleta seletiva do lixo, contribuindo assim para a melhora do planeta.

Nesse contexto de ideologia pós-moderna, que parece encantar a maioria, compreender a relação entre cidadania e educação se torna mais premente se quisermos que a educação contribua para uma postura crítica diante da realidade. Por isso a questão de saber qual cidadania queremos é de fundamental importância.

\section{A cidadania na ótica liberal}

A teoria liberal da cidadania (Kant, Hobbes, Locke e outros) tem como ponto de partida o pressuposto de que todos os homens são iguais e livres por natureza. As desigualdades sociais que hoje presenciamos teriam sido o resultado do próprio desdobramento da igualdade e da liberdade naturais. A busca da realização pessoal, consequência da própria liberdade de todos, faria com que os indivíduos se chocassem, inevitavelmente, entre si, dando origem a toda sorte de conflitos. Na ausência de qualquer elemento inibidor, estes conflitos tenderiam a se agudizar, pondo em perigo a própria sobrevivência não apenas de alguns, mas de todos os homens. Daí porque os homens ter-se-iam vistos obrigados a se organizar em sociedade e a instituir uma autoridade capaz de garantir que determinados limites não seriam ultrapassados. Desse modo, a desigualdade social era considerada legítima e constitutiva do mundo humano porque fruto do exercício da própria liberdade natural. Pretender suprimi-la equivaleria 
a pretender suprimir o próprio homem, de modo que o que deveria ser coibido seriam apenas os seus excessos.

Assim, para a doutrina liberal, como os homens não são individualmente iguais, é impossível querer que sejam socialmente iguais. Pelo contrário, a igualdade social é nociva, pois provoca uma padronização, uma uniformização entre os indivíduos, o que é um desrespeito à individualidade de cada um. "O liberalismo vê na igualdade social o fruto da intervenção autoritária, cujo resultado final é, em seu ponto de vista, uma restrição à personalidade individual”. (LASKI, 1973, p. 13).

No ideário liberal, a igualdade não abrange o campo das condições materiais. A desigualdade é perfeitamente coerente com o princípio liberal de que os indivíduos não são iguais em talentos e capacidades, daí decorrendo naturalmente eles não poderem ser iguais em riquezas. Para Voltaire, de acordo com Laski (1973, p. 154): "A propriedade igual para todos é uma simples quimera; só poderia ser obtida por espoliação injusta", concluindo logo a seguir: "é impossível em nosso infeliz mundo, que os homens que vivem em sociedade não se dividam em duas classes: pobres e ricos".

O conceito de igualdade entre os clássicos do liberalismo fica restrito ao plano das oportunidades. Rousseau parece ser a única exceção, embora não haja homogeneidade de pontos de vista entre os mais importantes autores que o comentam. Para Cunha (1977), por exemplo, a posição liberal exige a "igualdade perante a lei", igualdade de direitos entre os homens, igualdade civil. Tal posição defende que todos têm, por lei, iguais direitos à vida, à liberdade, à propriedade, à proteção das leis. Assim diz Rousseau (1968, p. 97):

em lugar de destruir a igualdade natural, o pacto fundamental (o estado) substitui, ao contrário, por uma igualdade moral e legítima, o que a natureza tinha podido pôr de desigualdade física entre os homens, para que, podendo ser desiguais em força e em gênio, todos se tornassem iguais por convenção e de direito.

Cunha (1977) afirma que daí não se pode concluir, portanto, que o princípio da igualdade implique na eliminação das desigualdades sociais entre os homens, principalmente das diferenças de riqueza. O próprio Rousseau (1968, p. 132) deixa isso claro:

[...] a respeito da igualdade, é preciso não entender por esta palavra que os graus de poder e de riquezas sejam absolutamente os mesmos; mas que, quanto ao poder, ele se encontra abaixo de toda violência, e nunca se exerce senão em virtude da posição social e das leis; e, quanto à riqueza, que nenhum cidadão seja suficientemente opulento para poder comprar outro, e que nenhum seja tão pobre que seja coagido a vender-se [...]. 
Seja como for, a igualdade parece ser é um pesado fardo que os liberais têm que carregar.

$\mathrm{Na}$ doutrina liberal, além da igualdade, pleiteia-se, antes de tudo, a liberdade individual, dela decorrendo todas as outras: liberdade econômica, intelectual, religiosa e política. Essa liberdade é a condição necessária para a defesa da ação e das potencialidades individuais, enquanto a não-liberdade é um desrespeito à personalidade de cada um.

O liberalismo usa do princípio da liberdade para combater os privilégios conferidos a certos indivíduos, em virtude de nascimento ou credo. O princípio da liberdade presume que um indivíduo seja tão livre quanto outro para atingir uma posição social vantajosa, em virtude de seus talentos e aptidões. (CUNHA, 1977)

Assim, o progresso geral da sociedade como um todo está condicionada ao progresso de cada indivíduo que obtém êxito econômico e, em última instância, á classe (grupo de indivíduos) que alcança maior sucesso material. (CUNHA, 1977, p. 30).

Laski (1973, p. 11) nos afirma que com relação às liberdades intelectuais, religiosas e políticas o liberalismo:

[...] sempre viu com maus olhos e desconfiança o controle sobre o pensamento e, na verdade, todo e qualquer esforço da autoridade do governo para impedir a livre atividade do indivíduo.

Assim, no liberalismo, embora não se falasse ainda em cidadania, a igualdade e a liberdade naturais eram a base para seu desenvolvimento futuro. E ainda que não o fossem de fato, todos os homens já eram, potencialmente, cidadãos, ou seja, sujeitos de direitos e deveres. O que assistimos daí para diante, será o processo concreto, histórico, extremamente complexo, de entificação da cidadania, sempre vista como um instrumento não para erradicar, mas para equilibrar as desigualdades sociais. (TONET, 2010).

Como conclusão nos afirma Tonet (2005, p. 49):

O que se pode ver, desse modo, é que, pelo menos na ótica liberal clássica a vinculação da democracia e da cidadania com a existência das classes sociais jamais é escamoteada. Do mesmo modo, jamais se afirma que elas sejam um instrumento para a supressão total das desigualdades sociais, justamente porque estas são consideradas insuprimíveis.

Assim, na doutrina liberal clássica, a ideia de igualdade sofre restrições desde o início e não tem o mesmo peso dos demais elementos que integram o credo liberal: individualismo, liberdade, propriedade. Como individualismo, liberdade e propriedade reinam soberanamente, igualdade e democracia sofrem restrições. (CUNHA, 1991). 
Como se pode ver, o fundamento para a doutrina clássica é, em essência, o mesmo. Não importa muito se os homens nascem iguais ou diferentes. Também não importam muito os diferentes argumentos para fundamentar a vida em sociedade. $\mathrm{O}$ que importa é que em todos encontramos como pressuposto o indivíduo autocentrado (egoísta) como unidade social última e irredutível. O ponto de partida é uma concepção de indivíduo como um ente ontologicamente anterior e fundante da sociedade. Uma das principais consequências é o fato de que a sociabilidade passa a ser instaurada pelo momento jurídico-político, ou seja, os homens só passam a existir como sociedade, no momento em que entra em cena, através do contrato social, a dimensão jurídico-política. Para Tonet (2005, p. 51):

Tudo isso não é nenhuma novidade. O que é novidade é o caráter de naturalidade, de verdade absoluta, de inquestionabilidade de que esta ideia é revestida. É considerada uma verdade tão evidente como o fato de que dois mais dois são quatro, de modo que não faria nenhum sentido questioná-la [...] Deste modo, explicitamente para os clássicos e implicitamente para os contemporâneos, os indivíduos são essencialmente regidos pelo interesse pessoal, o que faz com que as desigualdades sociais sejam uma consequência inevitável do processo social.

A ideologia pós-moderna em sua versão neoliberal não supera essa visão de cidadania. Pelo contrário, a reafirma agora em um novo contexto. Tal contexto se caracteriza por um clima político de mandonismo interno das elites nacionais e da dominação externa dos grupos internacionais, que impõem uma configuração socioeconômica na qual as condições de vida da imensa maioria da população são extremamente precárias. O aclamado processo de globalização da economia parece universalizar as vantagens do capital produtivo e as desvantagens do trabalho assalariado. Nessa situação a educação é interpelada com relação a seu papel histórico.

\section{A cidadania e a esquerda democrática.}

Não é fácil expor em termos resumidos - dada as diferenças entre os autores - as ideias desse conjunto que chamamos esquerda democrática a respeito da cidadania. Limitar-nos-emos a referir apenas dois pensadores: Carlos Nelson Coutinho e Norberto Bobbio. O primeiro de vertente marxista e o segundo não.

Bobbio rejeita explicitamente a ideia de uma igualdade natural. Afirma que a busca de um fundamento absoluto para os direitos humanos, derivando-os diretamente da natureza humana, foi uma ilusão dos jusnaturalistas. "Mas a natureza dos homens revelou-se muito frágil como fundamento absoluto de direitos irresistíveis" (BOBBIO, 
1988. p. 16), o que é demonstrado pelo fato de existirem direitos, chamados de naturais, que são incompatíveis entre si e, portanto, não podem ser, uns e outros, absolutamente fundados. Sua conclusão é que "O problema fundamental em relação aos direitos do homem, hoje, não é tanto o de justificá-los, mas o de protegê-los". (BOBBIO, 1988, p. 24). E diante da impossibilidade de encontrar esse fundamento absoluto, ele diz que o fundamento mais razoável, mas de modo algum absoluto, é o consenso intersubjetivo, ou seja, a aceitação geral, em um determinado período histórico. Segundo ele:

\begin{abstract}
A Declaração Universal dos Direitos do Homem representa a manifestação da única prova através da qual um sistema de valores pode ser considerado humanamente fundado e, portanto, reconhecido: e essa prova é o consenso geral acerca de sua validade. (BOBBIO, 1988, p. 26).
\end{abstract}

Portanto, em Bobbio, a igualdade não está calcada em uma perspectiva naturalista, consequência inevitável das relações sociais capitalistas, como contida na perspectiva liberal clássica. Os direitos universais dos homens são consequência de uma luta para estabelecer sua vigência positivada. Protegê-los é uma atividade política e, portanto, um embate ideológico. É, como falamos antes, um campo de batalha, necessitando de uma postura crítica para seu estabelecimento.

Para Coutinho (1980), embora a cidadania moderna tenha suas origens no interior da sociedade capitalista, ela não é uma categoria que se esgote nessa forma de sociabilidade. A história dos direitos, que se apresentam sob formas diversas - civis, políticos e sociais - revela, quando vista corretamente, que, muito mais do que uma concessão da burguesia, eles são o resultado de um duro processo de lutas da classe trabalhadora contra a burguesia.

Tal autor afirma que não faz sentido chamar a democracia e a cidadania de burguesas, ou seja, de particulares. Frisa que é contra o capital e não como um benefício outorgado por ele aos trabalhadores que se instaura uma sociedade democrática-cidadã. Para ele, não se trata de um processo linear, mas de avanços e recuos, de ganhos e perdas, no qual o capital sempre procura ceder o mínimo necessário, estando pronto a eliminar os ganhos dos trabalhadores quando estiverem em jogo os seus interesses vitais.

Coutinho (1980) insiste na ideia de que a cidadania e democracia não são valores meramente burgueses, quer dizer, particulares, mas valores de caráter universal. A respeito da democracia, após desenvolver uma argumentação acerca de seu valor 
universal e de que, portanto, não basta afirmar a importância da democracia da sociedade capitalista, ele conclui:

É preciso ir além dessa constatação e afirmar claramente que, tanto na fase de transição quanto no socialismo plenamente realizado, continuarão a ocorrer situações que só a democracia política será capaz de resolver no sentido mais favorável à explicitação do gênero humano. (COUTINHO, 1980, p. 24).

Diferentemente do liberalismo, para o qual o aperfeiçoamento da cidadania e da democracia jamais podem ultrapassar a ordem do capital, a esquerda democrática entende que, por haver uma contradição entre o capital, a cidadania e a democracia, estas só podem realizar-se em sua plenitude com a erradicação do capital. Afirma que "a cidadania plena [...] certamente incorpora os direitos civis (e não só os afirmados por Locke, mas também os gerados mais recentemente), mas não se limita a eles". (COUTINHO, 1980, p. 58).

Sobre essa cidadania plena ele afirma:

Por tudo isso, não hesitaria em dizer que a ampliação da cidadania - este processo progressivo e permanente de construção dos direitos democráticos que atravessa a modernidade - termina por se chocar com a lógica do capital. (COUTINHO, 1980, p. 66).

Após afirmar a existência de uma contradição entre a cidadania plena e as classes sociais conclui: "Se há alguma conclusão a tirar disso, ela me parece óbvia [...] só uma sociedade sem classes - uma sociedade socialista - pode realizar o ideal da plena cidadania ou, o que é o mesmo, o ideal da soberania popular e, como tal, da democracia”. (COUTINHO, 1980, p. 67-68).

Conclui-se disso que a cidadania não é um conceito fechado, impenetrável ao olhar político. Há pelo menos duas grandes matrizes do conceito de cidadania que informam sua conceitualização. Saber diferenciá-las é imprescindível para a construção de um processo educacional que possa ser, efetivamente, crítico e autônomo.

\section{Educação e cidadania no Brasil}

A relação entre educação e cidadania no Brasil perpassou, dialeticamente, as duas grandes matrizes mostradas acima. Embora uma delas tenha sido historicamente hegemônica, sua manutenção não foi mantida sem embates nem questionamentos. A luta entre as duas grandes concepções de cidadania sempre fez parte no processo político brasileiro, principalmente a partir do início do século XX, data da chegada do socialismo no Brasil. Como em todo jogo político há recuos e avanços, momentos de manutenção de posturas e momentos de ceder às pressões do grupo opositor. 
É fundamental, para entender o processo de construção da cidadania no Brasil, entender que nosso país foi colonizado por uma potência ibérica contrarreformista. Tal fato não é irrelevante para o processo educacional aqui construído. A tradição clássica, desembarcando junto com os jesuítas, determinou um tipo de educação e cidadania que teria vida longa na nossa cultura. O que confirma Cury (2014, p. 22):

O Brasil foi colonizado por uma potência ibérica, Portugal, cujo contexto de Metrópole articulado a um catolicismo contrarreformista determinou um modo autoritário de se relacionar com as populações nativas e com outras que aqui chegaram. Assim, os índios eram considerados "bárbaros" e os africanos, trazidos à força, tornaram-se escravos, "uma propriedade do outro".

Segundo esse autor, a decorrência disso é que, para esses contingentes humanos, a educação escolar não foi objeto de cogitação especial. Para eles bastava a doutrinação ou a catequese. Desse modo, o ler e o escrever eram considerados dispensáveis para quem não era visto senão como força de trabalho. Seguindo a lógica da perspectiva clássica, que trabalhava com a diferenciação entre superior e inferior, essas populações deveriam apenas ser ouvintes, escutando a palavra dos outros, no caso, dos jesuítas que traziam a "verdade" divina.

Essa característica perpassou toda a colônia. A educação nesse período foi consequência de duas condições objetivas: de um lado, a organização social e, de outro, o conteúdo cultural que foi transportado para a Colônia, através dos jesuítas. A primeira condição consistia na predominância de uma minoria de donos de terra e senhores de engenho sobre uma massa de agregados e escravos. Apenas àqueles cabia o direito à educação e, mesmo assim, em número restrito, já que deveriam estar excluídos dessa minoria as mulheres e os filhos primogênitos, aos quais se reservava a direção futura dos negócios paternos. Assim:

A escola era freqüentada somente pelos filhos homens que não primogênitos. Estes recebiam apenas, além de uma rudimentar educação escolar, a preparação para assumir a direção do clã, da família e dos negócios, no futuro. Era, portanto, a um limitado grupo de pessoas pertencentes à classe dominante que estava destinada a educação escolarizada. (ROMANELLI, 1982, p. 33)

A segunda condição consistia no conteúdo cultural de que se faziam portadores os padres jesuítas. Tal conteúdo se caracterizou por uma enérgica reação contra o pensamento crítico, que na Europa já começava a despontar, por um apego a formas dogmáticas de pensamento, revalorização da escolástica e pela afirmação da autoridade, quer da Igreja, quer dos antigos, pela prática de exercícios intelectuais com a finalidade 
de robustecer a memória e capacitar o raciocínio. (ROMANELLI, 1982). Tal situação impossibilitou a construção de uma cidadania plena em nosso país.

A primeira constituição do Brasil império outorgada em 1824, apesar de conter princípios liberais, pouco mudou, na prática, a situação que vinha desde a colônia. Ao sabor das forças políticas de então, tal Constituição não passou de uma colcha de retalhos atendendo tanto a princípios liberais quanto aos grandes fazendeiros escravistas. Tal contradição é bem posta por Cury (2014, p. 25):

\begin{abstract}
Trata-se de uma Constituição híbrida na qual convivem elementos liberais e suas garantias individuais dos cidadãos com o centralismo do Imperador e seu poder moderador. Mais do que híbrida, há uma contradição visível entre os princípios liberais e o estatuto da escravidão.
\end{abstract}

No que se refere à educação, essa Constituição incluiu a instrução primária e a gratuidade a todos os cidadãos. Assim, a instrução primária foi considerada um direito civil e político. No entanto, a cidadania incluía apenas os nascidos livres, os naturalizados e os libertos. Para os escravos e os índios, o acesso à educação primária pública estava interditado.

Esse "avanço" na educação brasileira não é sem razão. O período que se seguiu à Independência política viu também diversificar-se um pouco a demanda escolar: a parte da população que então procurava a escola já não era apenas pertencente à classe oligárquico-rural. A esta, aos poucos, se somava a pequena camada intermediária, que, desde cedo, percebeu o valor da escola como instrumento de ascensão social. Desde muito antes, o título de doutor valia tanto quanto o de proprietário de terras, como garantia para a conquista de prestígio social e de poder político. Por isso no dizer de Romanelli (1980, p. 37): "Era compreensível, portanto, que, desprovida de terras, fosse para o título que essa pequena burguesia iria apelar. A fim de firmar-se como classe e assegurar-se o status a que aspirava”.

Assim, também no Brasil império a educação se manteve como uma atividade para os grupos dominantes. Aos dominados sobrava uma educação pífia destinada a mantê-los nos limites estabelecidos pelas novas condições históricas. A cidadania que perpassava tal situação era a cidadania passiva, bem aos moldes do liberalismo que também informava a Constituição de 1824 e a primeira lei geral da educação de 1827.

$\mathrm{O}$ ato adicional de 1834 vai reconhecer uma certa autonomia das províncias e uma divisão de recursos fiscais. Houve a adoção de uma descentralização do ensino primário ao atribuir às províncias competência legislativa sobre a instrução pública. Tal 
situação não mudou o caráter de dualidade do sistema educacional, pelo contrário, o reafirmou:

O ensino superior, voltado para as elites, continuava competência dos poderes centrais dotados de impostos robustos. Já a instrução primária foi confiada às províncias com impostos de menor valor, resultando daí uma oferta dispersa e muito pouco abrangente. (CURY, 2014, p. 26).

A Constituição da República de 1891, que instituiu o sistema federativo de governo, consagrou também a descentralização do ensino, ou seja, a dualidade de sistemas, já que ela reservou à União o direito de criar instituições de ensino superior e secundário nos Estado e prover a instrução secundária no Distrito Federal, o que, consequentemente, delegava aos Estados competência para prover e legislar sobre educação primária.

Cury (2014) afirma que a Constituição de 1891 manteve um federalismo educacional quase nos mesmos moldes do Ato Adicional e, além disso, deixou a cargo da autonomia dos estados declarar ou não a gratuidade e a obrigatoriedade do ensino primário:

Os Estados teriam autonomia para, dentro de seus territórios, financiar com seus recursos essa etapa da educação escolar. Legalmente, os Estados podiam criar instituições de ensino secundário e superior dentro de seus espaços territoriais. (CURY, 2014, p. 27).

Nota-se, assim, um retrocesso com relação à Constituição de 1824. Nessa o ensino primário era considerado gratuito, portanto, um direito civil e político da nova nação, em que pese esses direitos serem apenas para uma minoria. Na Constituição de 1891, com a federalização, os Estados não têm a obrigatoriedade de declarar a gratuidade.

Registra-se que, só muito indiretamente, se pode dizer que a República de 1891 declarou a educação como um direito, além de não assinar (como o fazia a de 1824) a gratuidade. Tais atribuições ficaram por conta dos Estadosmembros. (CURY, 2014, p. 28).

Bem a gosto da cidadania liberal, nessa Constituição, o único ponto em que a União interveio foi na questão da laicidade do ensino. Essa retirada do ensino religioso dos currículos das escolas públicas foi uma das principais razões de conflito com a Igreja Católica.

Segundo Romanelli (1982, p. 41) essa situação era:

A consagração do sistema dual de ensino, que se vinha mantendo desde o Império. Era também uma forma de oficialização da distância que se mostrava, na prática, entre a educação da classe dominante (escola primária e 
escola profissional). Refletia essa situação uma dualidade que era o próprio retrato da organização social brasileira.

Em 1930 se dá o ponto alto de uma série de revoluções que se empenharam em promover vários rompimentos políticos e econômicos com a velha ordem social oligárquica. Sua meta maior era a implantação definitiva do capitalismo no Brasil. Através desses movimentos, o que se procurou foi um reajustamento constante dos setores novos da sociedade com o setor tradicional, do ponto de vista interno, e, destes dois, com o setor internacional, do ponto de vista externo.

Essa crise foi, portanto, uma necessidade de se reajustar o aparelho do Estado às novas necessidades da política e da economia, ou seja, de se substituir toda a estrutura política que contribuiu para criar e manter a crise econômica.

A Constituição de 1934 incorporou alguns princípios do Estado de Bem-Estar Social, quando tratou da ordem econômica e social e quando estabeleceu a educação como um direito de todos, tendo como finalidade o desenvolvimento da solidariedade humana. Nesse sentido tornava claro o dever do Estado para com a educação.

Essa Constituição garantiu a autonomia dos Estados e o sistema federativo. Impôs a todos os Estado e Municípios a instrução primária gratuita e obrigatória no ensino oficial e a vinculação de impostos para o financiamento, assumindo a educação como um direito. Segundo Cury (2014, p. 31):

\begin{abstract}
Essas realidades se apoiam em federalismo educacional, no qual as diretrizes e bases da educação nacional são da alçada da União, bem como a rede de ensino superior federal e o ensino superior da rede privada. Assim, compete aos Estados e Municípios a efetivação do direito à educação no âmbito do que hoje chamamos de educação básica, embora, concorrentemente, os Estados possam intervir no ensino secundário e no superior.
\end{abstract}

Assim, a Constituição de 1934 trouxe grandes avanços como a gratuidade e a obrigatoriedade do ensino primário, o plano nacional de educação e a institucionalização dos conselhos de educação. Adotou também a obrigatoriedade de destinar um percentual dos impostos para a educação, percentuais diferentes para a União, estados e Municípios.

Com a queda do Estado Novo em 1945 e a consequente redemocratização do país, a concepção corporativa de organização da sociedade vai cedendo, ainda que lentamente, à visão liberal, a qual procura restabelecer a cidadania política formal, cujo processo será interrompido com o golpe militar de 1964. A partir dos anos 70, o regime militar restaurou as funções que a educação desempenhara durante a ditadura Vargas: 
formação e treinamento de recursos humanos para o setor produtivo. Desse modo, a reforma educacional de 1971 visa recuperar a hegemonia da formação técnicoprofissional. Sobre esse momento nos informa Palma Filho (1998, p. 117):

Correndo o risco de sermos esquemáticos e reducionistas, poderíamos afirmar que a cidadania tutelada e a cidadania assistida, para ficarmos com a terminologia de Demo, encaram a educação como processo de preparação de recursos humanos, isto é, de treinamento, ao enfatizar o aspecto reprodutor, alçando para um segundo plano o caráter transformador que a educação possa vir a desempenhar no processo de formação de crianças e adolescentes. (PALMA FILHO, 1998, p. 117).

Cury (2014) afirma que entre 1946 e 1961, o que marcou o período foi a elaboração das Diretrizes e Bases da Educação Nacional, sob a forma de lei. No início dos debates o foco era a centralização versus descentralização. Mais tarde, entre 1959 e 1961, o debate ficou mais caloroso, já que o foco foi ensino público versus ensino privado. No final do período veio à luz a Lei 4.024/61, que confirmou a gratuidade, a obrigatoriedade, a vinculação orçamentária e o Plano Nacional de Educação. No entanto, confirmando o jogo de avanços e recuos, a caminhada de vai e vem da cidadania, pouco tempo depois, sobreveio o golpe de 1964 e a instauração do regime militar com cerceamento da democracia.

De volta ao regime democrático, a Constituição de 1988 reconheceu o direito à educação como o primeiro dos direitos sociais, assim como um direito do cidadão e dever do Estado. Estabeleceu princípios, diretrizes, regras, recursos vinculados e planos, de modo a dar substância a esse direito.

Ao explicar esse direito, elencou as formas de realizá-lo tais como gratuidade e obrigatoriedade com qualidade e com proteção legal, ampliada e com instrumentos jurídicos postos à disposição dos cidadãos, cria prerrogativas próprias para as pessoas em virtude das quais elas passam a usufruir de ou exigir algo que lhes pertence como tal. (CURY, 2014, p. 43).

Segundo Cury (2014), nesse momento a Constituição de 1988 impôs novos contornos organizacionais em vista de uma educação democrática própria da cidadania. Para isso, era necessário que houvesse algo comum que se expressou no conceito de educação básica. A escola existente até então não atendia à exigência de elevação quantitativa e qualitativa de novos padrões de uma educação escolar genuinamente democrática. (CURY, 2014).

A noção de comum associada à educação básica é um direito que intenciona o aprendizado de saberes válidos para toda e qualquer pessoa e responde a necessidades educativas do desenvolvimento humano como um patrimônio cultural. O comum vai mais além de um para todos, reportando-se a 
conhecimentos científicos válidos, à igualdade, à democracia, à cidadania e aos direitos humanos. (CURY, 2014, p. 49).

Como se pode ver nesse panorama extremamente resumido do caminhar da cidadania nos textos legais brasileiros relacionados à educação, percebe-se uma tensão entre uma cidadania restrita (passiva) e uma cidadania com uma amplitude maior, sem nunca chegar a sua plenitude. No entanto, tal tensão não elimina um certo avanço. A educação brasileira deu um salto qualitativo e quantitativo inegável desde sua introdução com os Jesuítas

Não há dúvidas que houve um avanço na questão da cidadania. Na colônia, onde a relação entre a classe dominante e a dominada era de submissão, a consequência natural de tal relação de forças foi a ausência de cidadania. O Império, proclamado sob a bandeira liberal, embora mantendo, na maioria dos casos, a mesma estrutura da colônia, introduz princípios de igualdade e liberdade, mesmo que na ótica liberal já vista acima. A República, instaurada em um contexto de crise do modelo agrário-exportador e tentativa de incentivo à industrialização, precisa robustecer um pouco mais essa cidadania, sob pena de não se adequar à nova fase do capitalismo industrial. E a chamada Nova República, adentrando já no início da fase globalizada do modo de produção capitalista, passa a dar mais atenção para a cidadania, a ponto de a Constituição de 1998 ser chamada de Constituição cidadã.

A partir da década de 1990 o neoliberalismo se instaura definitivamente em nosso país. Como vimos, tal ideologia não supera, mas reafirma a ótica liberal em um contexto de globalização. Uma educação como direito fundamental do indivíduo cede lugar para uma visão de educação marcadamente mercadológica. Nesse contexto a cidadania se torna demasiadamente acanhada em relação aos direitos fundamentais do ser humano. Os direitos sociais são fortemente atacados em nome de uma concepção individualista e empresarial de educação.

No entanto, fica a pergunta: qual cidadania percorreu hegemonicamente a história brasileira? Qual cidadania queremos? Qual a relação entre educação e cidadania? Essas perguntas não são inocentes. As respostas só terão sentido se entendermos que a cidadania é um desses conceitos escorregadios que, sem uma análise mais profunda e crítica, mais confundem que elucidam. Por isso, a questão central desse texto permanece aberta: de que cidadania estamos falando quando propomos que a educação deve educar para a cidadania? 
Concluindo, entendemos que uma educação voltada para a construção de uma cidadania democrática não pode se orientar apenas por valores advindos das forças do mercado. Ao contrário, deve centrar-se em um currículo que capacite o ser humano para o desempenho de atividades que pertencem aos três domínios explicitados por Severino (1994, p. 100): “A vida em sociedade, a atividade produtiva e a experiência subjetiva, a integração dos homens no tríplice universo do trabalho, da simbolização subjetiva e das relações políticas". 


\section{REFERÊNCIAS}

BOBBIO, Norberto. A Era dos Direitos. Rio de Janeiro: Campos, 1992.

COUTINHO, Carlos Nelson. A democracia como valor universal. São Paulo: Ciências Humanas, 1980.

COUTINHO, Carlos Nelson. Democracia e Socialismo. São Paulo: Cortez, 1992.

CUNHA, Luiz Antônio. Educação e desenvolvimento social no Brasil. Rio de Janeiro: Francisco Alves, 1977.

CURY, Carlo Roberto Jamil. Educação e Direito à educação no Brasil: um histórico pelas Constituições. Belo Horizonte: Mazza Edições, 2014.

IANNI, Octávio. Globalização e Neoliberalismo. São Paulo em Perspectiva, São Paulo, v.12, n. 2, p. 27-32, abr./jun. 1998.

LASKI, Harold J. O liberalismo Europeu. São Paulo: Mestre Jou, 1973.

PALMA FILHO, João Cardoso. Cidadania e educação. Cadernos de pesquisa, São Paulo, v.21, n.104, p. 101-121, 1998.

ROMANELli, Otaíza Oliveira. História da Educação no Brasil. Petrópolis: Vozes, 1980.

ROUSSEAU, J. Do Contrato Social. Lisboa: Portugália, 1968.

SEVERINO, Antônio Joaquim. Educação, trabalho e cidadania: a educação brasileira e o desafio da formação humana no atual cenário histórico. São Paulo em Perspectiva, São Paulo, v. 14, n. 2, Abr./Jun. 2000.

TONET, Ivo. Educação, cidadania e emancipação humana. Ijuí: Ed Unijuí, 2005. 